\title{
Comparação do efeito nas culturas de humor aquoso de gatifloxacina $0,3 \%$ aplicado três dias antes de facoemulsificação e e antes do pré-operatório
}

\author{
Comparison of the effect on aqueous humor culture \\ of gatifloxacin $0.3 \%$ applied three days before \\ phacoemulsification and before preoperative
}

Paulo Augusto Hidalgo de Menezes ${ }^{1}$, Wilson Takashi Hida², Alexandre Almeida Brasil ${ }^{3}$, Diana Linhares Leins Peixoto $^{4}$, Iris de Souza Yamane ${ }^{5}$, João Brasil Vita Sobrinho ${ }^{6}$, Celso Takashi Nakano ${ }^{7}$, Amaryllis Avakian ${ }^{8}$

\section{ResUmo}

Objetivo: Determinar o efeito de gatifloxacina $0,3 \%$ tópica, nas culturas de humor aquoso humano, instilada quatro vezes ao dia por três dias antes de facoemulsificação comparada a uma gota gatifloxacina $0,3 \%$ tópica instilada imediatamente antes da cirurgia. Métodos: Trinta e sete pacientes com catarata sem outras afecções oculares foram distribuídos aleatoriamente nos Grupos A e B antes da facoemulsificação. Os pacientes do Grupo A receberam uma gota de gatifloxacina $0,3 \%$ imediatamente antes da cirurgia e o Grupo B recebeu gatifloxacina $0,3 \%$ quatro vezes ao dia três dias antes do procedimento. Após a facoemulsificação, o humor aquoso foi aspirado e semeado em meios de ágar-sangue, ágar-chocolate, Saboraud e TSB. Foi realizado esfregaço para bacterioscopia. Resultados: O Grupo B apresentou $40 \%$ das lâminas bacterioscópicas com cocos gram +. O Grupo B apresentou $17,6 \%$ de cocos gram + na bacterioscopia, estes resultados não foram estatisticamente significativos $(\mathrm{p}=0,098)$. Cinco casos $(25 \%)$ do Grupo A apresentaram culturas positivas para Staphylococos epidermidis, resultado significativamente maior do que o Grupo B, que não apresentou nenhuma cultura positiva para bactérias ou fungos. Conclusão: Neste estudo, a gatifloxacina $0,3 \%$ instilada três dias antes da facoemulsificação diminuiu significativamente o número de culturas do humor aquoso positivas quando comparada à instilação imediata de uma gota.

Descritores: Agentes antibacterianos/administração \& dosagem; Facoemulsificação; Bactéria/isolamento \& purificação

\footnotetext{
${ }^{1}$ Estagiário do Setor da Catarata da Faculdade de Medicina da Universidade de São Paulo - USP - São Paulo (SP), Brasil; Médico Assistente do Serviço de Oftalmologia do Hospital Beneficência Portuguesa de São Paulo - São Paulo (SP), Brasil;

${ }^{2}$ Pós-graduando (Doutorado) do Setor da Catarata da Faculdade de Medicina da Universidade de São Paulo - USP - São Paulo (SP), Brasil; Assistente do Setor da Catarata da Santa Casa de Misericórdia de São Paulo - SCMSP - São Paulo (SP), Brasil;

${ }^{3}$ Estagiário do Setor da Catarata da Faculdade de Medicina da Universidade de São Paulo - USP - São Paulo (SP), Brasil; Estagiário do Setor da Catarata da Santa Casa de Misericórdia de São Paulo - SCMSP - São Paulo (SP), Brasil;

${ }^{4}$ Estagiário do Setor da Catarata da Faculdade de Medicina da Universidade de São Paulo - USP - São Paulo (SP), Brasil;

${ }^{5}$ Estagiário do Setor de Catarata e Cirurgia Refrativa Departamento de Oftalmologia da Faculdade de Medicina da Universidade de São Paulo - USP - São Paulo (SP), Brasil;

${ }^{6}$ Mestrado pelo Departamento de Oftalmologia da Universidade Federal de São Paulo - UNIFESP - São Paulo (SP), Brasil;

${ }^{7}$ Assistente do Departamento de Oftalmologia da Faculdade de Medicina da Universidade de São Paulo - USP - São Paulo (SP), Brasil;

${ }^{8}$ Chefe Assistente do Setor da Catarata da Faculdade de Medicina da Universidade de São Paulo - USP - São Paulo (SP);
}

Serviço de Oftalmologia do Hospital Beneficência Portuguesa de São Paulo - São Paulo (SP), Brasil.

Recebido para publicação em: 30/6/2010 - Aceito para publicação em 21/11/2010 


\section{INTRODUÇÃO}

$\Delta$ profilaxia da endoftalmite na cirurgia de catarata tem aspectos peculiares que fazem com que um método definitivo ainda não tenha sido estabelecido $^{(1)}$. A incidência baixa de endoftalmite dificulta estudos que tenham valor estatístico significante. A quantidade de variáveis antes, durante e depois da cirurgia faz com que, mesmo em estudos de comparações de incidências de infecção, seja difícil isolar um fator responsável pela endoftalmite ${ }^{(1,2)}$. Apesar de todas as dificuldades, o risco de perda visual importante em um procedimento cirúrgico que deveria recuperar a visão do paciente exige a identificação e eliminação de fatores causadores de endoftalmite. Como a causa da endoftalmite infecciosa é a presença de agente infeccioso, a eliminação de qualquer agente infectante antes que ocorra a cirurgia pode diminuir a chance da ocorrência de endoftalmite.

A profilaxia da infecção na remoção de catarata com implante de lente intraocular procura eliminar a presença de agentes etiológicos potencialmente infecciosos antes do procedimento. Alguns dos métodos de profilaxia já foram descritos: iodopovidona imediatamente antes do procedimento, uso de antibióticos imediatamente antes do procedimento, uso de antibióticos depois do procedimento e combinações destes métodos com diferentes formas de administração (subconjuntival, intracameral, tópico) ${ }^{(1,3,4)}$.

As quinolonas de quarta geração estão disponíveis no mercado há dois anos e apresentam espectro de ação duplo contra bactérias gram-negativas e gram-positivas, incluindo as bactérias mais comuns detectadas como causas de endoftalmite após cirurgia de catarata ${ }^{(5)}$. Alguns estudos mostram penetração das quinolonas de quarta geração (moxifloxacina $0,5 \%$ e gatifloxacina $0,3 \%$ ) no humor aquoso, atingindo valores maiores do que as concentrações inibitórias mínimas para diversas bactérias ${ }^{(6,8)}$. No entanto, não há estudos que mostram efeitos destas medicações sobre culturas no humor aquoso. O objetivo deste estudo é verificar e comparar a presença de bactérias ou fungos no humor aquoso com o uso de uma quinolona de quarta geração, a gatifloxacina $0,3 \%$, imediatamente antes da cirurgia ou três dias antes da cirurgia.

\section{Métodos}

Este estudo foi realizado no Departamento de Oftalmologia do Hospital da Beneficência Portuguesa (SP), após aprovação do comitê de ética do Hospital.
Trinta e sete pacientes (18 do sexo masculino e 19 do sexo feminino) com catarata sem outras afecções oculares foram distribuídos de forma aleatória em dois grupos: grupo $A(n=20)$ e grupo $B(n=17)$. Após orientação sobre o procedimento e estudo, os pacientes assinaram termo de consentimento livre esclarecido. Ambos os grupos foram submetidos a facoemulsificação com implante de lente intraocular realizados pelo mesmo cirurgião. Antes da cirurgia todos os pacientes receberam anestesia tópica com sedação, seguido por uma gota de iodopovidona $5 \%$ colírio, colocação de campos cirúrgicos e facoemulsificação com implante de lente intraocular dobrável sem sutura de córnea. O grupo A recebeu antes da cirurgia uma gota de gatifloxacina colírio e o grupo B usou o colírio de gatifloxacina três dias antes da cirurgia de 6 em 6 horas.

Após a facoemulsificação uma amostra de 0,1 cc de humor aquoso foi coletada e semeada em Ágar-Sangue, Agar-chocolate, Saboraud e TSB (Tryptic Soy Broth). Antes de semear a amostra foi realizado esfregaço em lâmina para bacterioscopia. Os resultados da cultura foram tabelados e o estudo estatístico utilizado foi o teste de igualdade de duas proporções com intervalo de confiança de $95 \%$.

\section{Resultados}

Os quadros 1 e 2 mostram os resultados das culturas para os pacientes de ambos os grupos. $\mathrm{Na}$ bacterioscopia oito (40\%) pacientes do Grupo A apresentaram cocos gram-positivos e $2(10 \%)$ pacientes apresentaram restos celulares. No grupo B a bacterioscopia detectou cocos gram-positivos em $3(17,6 \%)$ pacientes e restos celulares em 1 paciente (5,9\%). Não houve diferença significativa entre o número de pacientes do Grupo A e do Grupo B com bacterioscopia negativa, embora, devido ao valor p próximo ao limite de confiança, pode-se afirmar que há tendência de bacterioscopias negativas no Grupo B ( $\mathrm{p}=0,098)$.

Houve crescimento de S. epidermidis em placas de cinco $(25 \%)$ pacientes do grupo A. Não houve crescimento de bactérias em nenhuma das culturas coletadas do grupo B. O teste de igualdade de proporções mostrou uma quantidade significativamente menor de culturas positivas no Grupo B ( $p=0,027)$.

\section{DiscuSSÃO}

Diversos trabalhos avaliam a presença de agentes infecciosos no humor aquoso após a cirurgia de catarata por extração extracapsular ou por facoemulsificação. 


\section{Quadro 1}

Resultados da bacterioscopia e da cultura do humor aquoso para os pacientes do Grupo A (Gatifloxacina 0,3\% 1 gota antes da cirurgia)

\begin{tabular}{lll}
\hline Paciente & Bacterioscopia & Cultura \\
\hline JGC & Cocos Gram + & S. epidermidis \\
JCSM & Cocos Gram + & S. epidermidis \\
PRPB & Cocos Gram + & S. epidermidis \\
ELD & Cocos Gram + & negativa \\
NHC & Cocos Gram + & negativa \\
PC & Cocos Gram + & negativa \\
DB & Cocos Gram + & S. epidermidis \\
LF & negativa & negativa \\
GM & negativa & negativa \\
FM & negativa & negativa \\
GM & negativa & negativa \\
JCM & negativa & negativa \\
MR & negativa & negativa \\
MGSB & Citologia: restos celulares & negativa \\
FAF & negativa & negativa \\
MIMZ & negativa & negativa \\
APO & negativa & negativa \\
AFCB & Citologia: restos celulares & negativa \\
AA & negativa & negativa \\
HR & Cocos Gram + & S. epidermidis \\
\hline
\end{tabular}

\section{Quadro 2}

Resultados da bacterioscopia e da cultura do humor aquoso para os pacientes do Grupo B (Gatifloxacina $0,3 \% 4 x /$ dia 3 dias antes da cirurgia)

\begin{tabular}{lll}
\hline Paciente & Bacterioscopia & Cultura \\
\hline RGM & negativo & negativo \\
JBCN & Cocos Gram + & negativo \\
VMR & negativo & negativo \\
NM & negativo & negativo \\
LVB & negativo & negativo \\
MAM & negativo & negativo \\
SVB & negativo & negativo \\
BJ & Citologia: restos celulares & negativo \\
YVG & negativa & negativo \\
LG & negativa & negativo \\
FH & negativa & negativo \\
FI & negativa & negativo \\
JM & negativa & negativo \\
SH & negativo & negativo \\
AB & negativa & negativo \\
PB & Cocos Gram + & negativo \\
EG & Cocos Gram + & negativo \\
\hline
\end{tabular}

A quantidade de culturas positivas não varia de acordo com a técnica, e a incidência de culturas positivas já foi relatado como sendo de $43 \%{ }^{(9,10)}$.

Estudos diversos avaliam culturas no humor aquoso após o uso de antibióticos com diferentes formas de administração (tópica, subconjuntival, intracameral, administrado durante a cirurgia diluído na solução salina balanceada) e após o uso de iodopovidona imediatamente antes da cirurgia ${ }^{(1,11,12)}$. Nestes estudos há tendências observadas de diminuição das culturas positivas, porém não há diferenças estatisticamente significativas. Os antibióticos avaliados por meio de cultura do humor aquoso pós-operatório até o momento foram gentamicina, vancomicina, ofloxacina e levofloxacina ${ }^{(11,12)}$. Embora hajam estudos de concentração de gatifloxacina no humor aquoso, não há estudos de culturas do humor aquoso após administração prévia ${ }^{(8)}$.

Neste estudo, o grupo que recebeu gatifloxacina $0,3 \%$ tópica $4 \mathrm{x}$ ao dia três dias antes da cirurgia não apresentou nenhuma cultura positiva para bactérias ou fungos no humor aquoso coletado após a cirurgia. Este resultado foi significativamente menor do que o grupo tratado com uma gota de gatifloxacina $0,3 \%$ somente no dia da cirurgia.

Optamos por não alterar a rotina pré-operatória e pós-operatória do cirurgião para não acrescentar variáveis que não pudessem ser controladas, tais como técnica cirúrgica ou uso de iodopovidona. Nota-se que mesmo com os cuidados operatórios padrões de antissepsia e uso de campo cirúrgico ainda observouse a presença de bactérias no humor aquoso. Mesmo com o cultivo de bactérias nenhum dos casos apresentou endoftalmite, provavelmente devido ao clearance do humor aquoso e sua capacidade em remover microorganismos.

Na profilaxia pré-operatória para infecções pósoperatórias, o cirurgião que considerar o uso de gatifloxacina deve saber que o uso com três dias de antecedência, quatro vezes ao dia, leva a uma diminuição significativamente menor no número de culturas positivas do que a instilação pré-operatória imediata do mesmo antibiótico.

\section{Conclusão}

Neste estudo, a gatifloxacina $0,3 \%$ instilada três dias antes da facoemulsificação diminuiu significativamente o número de culturas positivas do humor aquoso quando comparada à instilação imediata de uma gota. 


\section{Abstract}

Purpose: To determine the effect on human aqueous humor cultures of topical gatifloxacin $0.3 \%$ applied four times a day three days before phacoemulsification compared to topical gatifloxaxin $0.3 \%$ applied and sameday surgery. Methods: Thirty-seven patients with cataract without other ocular diseases were randomly assigned to Groups A and B before phacoemulsification. Group A received topical gatifloxacin $0.3 \%$ same-day surgery and Group B received gatifloxacin 0.3\% four times a day three days before phacoemulsification. After the procedure the aqueous humor was aspirated for cultures on agarblood, agar-chocolate, saboraud and TSB and smeared for bacterioscopy. Results: Group A presented $40 \%$ of the bacterioscopies with cocci gram +, Group B presented $17.6 \%$ of the bacterioscopies with cocci gram + . These results are not statistically significant $(p=0,098)$. Five cases (25\%) from Group A presented positive cultures for $S$. epidermidis, which was significantly higher than Group B, which did not present positive cultures for any bacteria or fungus ( $p=0,027)$. Conclusion: Gatifloxacin $0.3 \%$ applied three days before phacoemulsification significantly lowered the rate of positive aqueous humor cultures when compared to immediate application of this antibiotic before surgery in this study.

Keywords: Antibacterial agents/administration \& dosage; Phacoemulsification; Bacteria/isolation \& purification

\section{REFERÊNCIAS}

1. Ciulla TA, Starr MB, Masket S. Bacterial endophthalmitis prophylaxis for cataract surgery: an evidence-based update. Ophthalmology. 2002;109(1):13-24. Comment in: Ophthalmology. 2003;110(8):1668; author reply 1669. Ophthalmology. 2003;110(8):1667; author reply 1667-8.

2. Ta CN, Egbert PR, Singh K, Blumenkranz MS, de Kaspar HM. The challenge of determining aqueous contamination rate in anterior segment intraocular surgery. Am J Ophthalmol. 2004;137(4):662-7.
3. Sobaci G, Tuncer K, Tas A, Ozyurt M, Bayer A, Kutlu U. The effect of intraoperative antibiotics in irrigating solutions on aqueous humor contamination and endophthalmitis after phacoemulsification surgery. Eur J Ophthalmol. 2003;13(910):773-8. Comment in: Eur J Ophthalmol. 2005;15(1):173; author reply 174 .

4. Donnenfeld ED, Perry HD, Snyder RW, Moadel R, Elsky M, Jones H. Intracorneal, aqueous humor, and vitreous humor penetration of topical and oral ofloxacin. Arch Ophthalmol. 1997;115(2):173-6.

5. Mather R, Karenchak LM, Romanowski EG, Kowalski RP. Fourth generation fluoroquinolones: new weapons in the arsenal of ophthalmic antibiotics. Am J Ophthalmol. 2002;133(4):463-6.

6. Kleinmann G, Larson S, Neuhann IM, Hunold AC, LeBoyer $\mathrm{R}$, Hickman S, et al. Intraocular concentrations of gatifloxacin and moxifloxacin in the anterior chamber via diffusion through the cornea using collagen shields. Cornea. 2006;25(2):209-13.

7. Callegan MC, Ramirez R, Kane ST, Cochran DC, Jensen H. Antibacterial activity of the fourth-generation fluoroquinolones gatifloxacin and moxifloxacin against ocular pathogens. Adv Ther. 2003;20(5):246-52.

8. Kim DH, Stark WJ, O'Brien TP, Dick JD. Aqueous penetration and biological activity of moxifloxacin $0.5 \%$ ophthalmic solution and gatifloxacin $0.3 \%$ solution in cataract surgery patients. Ophthalmology. 2005;112(11):1992-6.

9. Dickey JB, Thompson KD, Jay WM. Anterior chamber aspirate cultures after uncomplicated cataract surgery. Am J Ophthalmol. 1991;112(3):278-82.

10. Mistlberger A, Ruckhofer J, Raithel E, Müller M, Alzner E, Egger SF, Grabner G. Anterior chamber contamination during cataract surgery with intraocular lens implantation. J Cataract Refract Surg. 1997;23(7):1064-9. Comment in: J Cataract Refract Surg. 2003;29(8):1465-6; author reply 1446.

11. Cekiç O, Batman C, Totan Y, Yasar U, Basci NE, Bozkurt A, et al. Aqueous humour levels of topically applied ciprofloxacin and ofloxacin in the same subjects. Eye (Lond). 1999;13 (Pt 5):656-9.

12. Mendivil Soto A, Mendivil MP. The effect of topical povidone-iodine, intraocular vancomycin, or both on aqueous humor cultures at the time of cataract surgery. Am J Ophthalmol. 2001;131(3):293-300.
Endereço para correspondência
Wilson Takashi Hida
Rua Afonso de Freitas, no 488 - apto.61 - Paraíso
CEP 04006-052 - Rio de Janeiro (RJ), Brasil
E-mail: witaks@yahoo.com.br 